\title{
Need to adopt best practices in teaching communication skills
}

\author{
Karunathilake I.M.
}

\begin{abstract}
Introduction
The importance of communication skills in doctor-patient relationship
\end{abstract}

Effective communication between the patient and the healthcare professional is at the core of delivering high quality healthcare. It has a positive relationship with the higher rates of patient recovery, therapy compliance and lower rates of medical malpractice.

Effective communication is the foundation to obtain an accurate clinical history to prescribe the treatments most effectively by understanding the socio-cultural and financial background of the patient, which enhances the patient compliance. Improved patient satisfaction invariably reduces the work stress and improves job satisfaction of the physicians (Madsen et al., 2005).

\section{The process of doctor-patient communication}

Communication is a two-way process of giving and receiving information through any number of channels which is influenced by many factors such as knowledge, self-concept, ethical and cultural factors. There are some basic principles for developing good communication skills such as listening to patients, empathy and paying attention to verbal, non-verbal and paraverbal commands

A routine doctor-patient communication can be broken down to six main steps. i.e., initiating the session, gathering information, explanation and planning and closing the session.

Corresponding Author:

Professor and Head,

Department of Medical Education,

Head, WHO Collaborating Centre for Medical Education,

Faculty of Medicine, University of Colombo, Sri Lanka.

Email:karunathilake@hotmail.com
The doctor must ensure that the patient is comfortable, secure and assured of privacy. Active-empathic listening is an important component of effective doctor-patient communication. Ideally, as the patient comes in, he/she should be greeted and a seat should be offered verbally or by gesture.

Challenging situations encountered during doctor-patient communication

Communicating with special categories of patients such as terminally ill patients, small children, those who are affected by war or disasters, marginalized social groups, victims of domestic or sexual violence can be challenging and call for a unique set of skills mix. Doctors need to be trained in those special skills and techniques.

There are several barriers for effective communication. Lack of knowing the importance of adequately informing the patients is one among them. Incorporating communication skills to the core curriculum of undergraduate medical education is vital to overcome this barrier. Language also becomes a barrier to a certain extent. It is not unusual for patients to speak in their local languages. In these instances intervening of a translator creates a vast communication gap between the doctor and the patient. In overcrowded clinical setups, which are commonly found in Sri Lanka, effective doctor patient communication is often neglected since the main concern of the doctor becomes the crowd clearance.

Teaching and assessing communication skills in medical education

Communication has been identified as an essential clinical skill and is included in most medical education curricula worldwide. The General Medical Council of the UK advocates that by the end of their undergraduate course,

DOI: http://doi.org/10.4038/seajme.v13i1.55

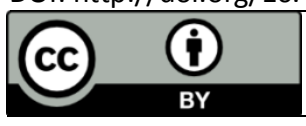

(c) SEAJME. This is an Open Access article distributed under the terms of the Creative Commons Attribution

License (http://creativecommons.org/licenses/by/4.0/), which permits unrestricted use, distribution, and reproduction in any medium, provided the original author and source are credited 
medical students should be proficient in communicating with patients. Effective Communication is a core competency identified by the Accreditation Council for Graduate Medical Education (ACGME) in the USA (Lofdahl et al., 2005). The Behavioural Sciences Stream (BSS), which was introduced as during the 1995 curriculum change of The Faculty of Medicine, University of Colombo, Sri Lanka was a major initiative of training communication skills, ethics and professionalism (Jayasinghe, 2002; Galappatthy et al., 2002; Olupeliyawa et al., 2007). South Asian medical schools needs to adopt international best practices in teaching and assessing communication.

It is important to assess communication skills to ensure the achievement of competent communication. The written assessments alone cannot effectively assess students' performance in communication skills. The skills elements should be prioritized in main assessment methods, i.e. practical or performance-based assessment. Cognitive or written assessment can support the practical assessment to know the student's understanding on communication concept. Communication skills assessment may be done as students 'perception, written reports, written tests on medical interviews, Objective Structured Clinical Examinations (OSCE), selfrating scales, direct observations and video observations.

Valid and reliable assessment of communication skills can be challenging. A range of assessment methods and tools including Objective Structured Clinical Examination (OSCE) and work place based assessment are available. Clearly defined target skills and well-trained observers can provide a high reliability (Hodges et al., 1996).

Successful communication skills assessment is done at three levels;

1. Subjective perception about knowledge on the manner of communication which can be achieved by a written test or a selfevaluation

2. Objective assessment of communication skills, e.g. with OSCE

3. Assessing an output aspect of communication process, e.g. simulated patient's perception

\section{Conclusion}

Training and assessment of communication skills can pose several challenges to medical educationists. Understanding that the benefits of teaching and assessing communication skills outweigh the challenges of implementing can motivate teachers and learners. The ideal approach of teaching communication skills is practice based, including on the job training and role modeling. Communication skills training should continue longitudinally throughout the medical curriculum rather than be taught as a single module, so that students will be able to communicate effectively in different settings and contexts.

\section{References}

Galappatthy, P., Abdulla, A.A., Goonesekera, D.T., Hanwella, D.R., Fernando, S.S.D., Seneviratne, R. De A. \& Goonaratna C. (2002) The impact of behavioural science inputs relevant to clinical work during professorial clinical rotations: perceptions of final year medical students of the University of Colombo, Presented at International Conference on Curriculum Change in Medical Schools, Faculty of Medicine, Colombo, Sri Lanka: 2002.

Hodges, B., Turnbull, J., Cohen, R., Bienenstock, A. \& Norman, G. (1996) Evaluating communication skills in the OSCE format: reliability and generalizability, Medical Education, 30, 1, pp. $38-43$

Jayasinghe, S. (2002) A new curriculum: a shift for innovation, Reforming medical curriculum, lessons from an established medical school in Sri Lanka, Colombo: Jayasinghe, pp. 21-22

Lofdahl, T., Nilsson, E., Haffling, A.C. \& Hakansson, A. (2005) Consultation skills training is necessary in medical education, Evaluation by student questionnaire and focus group interviews, Lakartidningen, 102, 16, pp. 12391240 .

Madsen, P.L., Pedersen, B.D. \& Aspegren, K. (2005) Communication skills training for medical students: from the simple to the complex, Ugeskrift for laeger, 167, 38, pp. 3581-3583

Olupeliyawa, A., Gooneratne, K., Tillakaratne, M.S., Wickramasinghe, K.K., Karunathilake, I.M. \& Samarasekera, D. (2007) Graduates' Perceptions regarding their final year training, South East Asian Journal of Medical Education, 1, pp. 25-29 